\title{
Evaluating the effectiveness of a CRSCE- based de-escalation training program among psychiatric nurses: a study protocol for a cluster randomized controlled trial
}

Junrong Y $\mathrm{e}^{1,2^{*+}} \mathbb{D}$, Aixiang Xiao ${ }^{1,3+}$, Chen Wang ${ }^{4+}$, Zhichun Xia ${ }^{5}$, Lin Yu ${ }^{3}$, Sijue Li ${ }^{1,3}$, Jiankui Lin ${ }^{1}$, Yao Liao ${ }^{6}$, Yu Xu $\mathrm{u}^{7}$ and Yun Lei Zhang ${ }^{6}$

\begin{abstract}
Background: The high incidence of workplace violence (WPV) in clinical mental health settings has caused a series of negative impacts on nurses, which has subsequently increased public concern. De-escalation (DE) is recommended as a training program which aims at providing nurses with skills and strategies to more effectively respond and manage WPV. Very few studies have examined the effectiveness of DE training, with current studies possessing various limitations due to their design and small sample sizes. By using a cluster randomized controlled design, the proposed study aims to evaluate the effectiveness of a CRCSE-based DE training programs among psychiatric nurses.

Method: A cluster randomized controlled trial, with a 6-month follow-up period after the end of the intervention, will be conducted among psychiatric hospitals in Guangdong, China. The randomization unit is each involved psychiatric hospital. Participants in the control group will be assigned to routine WPV management training, participants of the intervention group will undergo the same training while additionally receiving DE training. The DE training will include the following five modules: communication, response, solution, care, and environment (CRSCE). Primary outcomes are objective clinical indicators, which will be extracted from the information systems of the enrolled hospitals. These include the incidence of WPV, injuries caused by WPV, and the use of coercion (physical restraint and seclusion) by nurses. Secondary outcomes, aims at evaluating the effects of DE training on nurses, include the capacity of $D E, D E$ confidence, level of job burnout, and professional quality of life. Data will be collected at baseline $\left(T_{0}\right)$, at 3 months ( $T_{1}$, intervention completed), and at 6 months after intervention ( $T_{2}$, follow-up).

\footnotetext{
* Correspondence: yejunrong1580@qq.com

†Junrong Ye, Aixiang Xiao and Chen Wang contributed equally to this work.

'Department of Nursing Administration, Affiliated Brain Hospital of

Guangzhou Medical University (Guangzhou Huiai Hospital), Guangzhou

510370, China

${ }^{2}$ Department of Social Psychiatry, Affiliated Brain Hospital of Guangzhou

Medical University (Guangzhou Huiai Hospital), Guangzhou, China

Full list of author information is available at the end of the article
}

(C) The Author(s). 2020 Open Access This article is licensed under a Creative Commons Attribution 4.0 International License, which permits use, sharing, adaptation, distribution and reproduction in any medium or format, as long as you give appropriate credit to the original author(s) and the source, provide a link to the Creative Commons licence, and indicate if changes were made. The images or other third party material in this article are included in the article's Creative Commons licence, unless indicated otherwise in a credit line to the material. If material is not included in the article's Creative Commons licence and your intended use is not permitted by statutory regulation or exceeds the permitted use, you will need to obtain permission directly from the copyright holder. To view a copy of this licence, visit http://creativecommons.org/licenses/by/4.0/ The Creative Commons Public Domain Dedication waiver (http://creativecommons.org/publicdomain/zero/1.0/) applies to the data made available in this article, unless otherwise stated in a credit line to the data. 
(Continued from previous page)

Discussion: This study will offer trial-based evidence of the efficacy of a DE training program targeted at WPV among psychiatric nurses. DE training is expected to reduce both the total incidence and negative impacts of WPV, with additional improvements in psychiatric nurses' coping skills.

Trial registration: Chinese Clinical Trial Registry, ChiCTR1900022211. Prospectively registered on 30 March 2019.

Keywords: Cluster randomized controlled trial, De-escalation, Protocol, Training program

\section{Background}

Workplace violence (WPV) includes any act or threat occurring at a person's work site involving physical violence, harassment, intimidation, and other threatening or disruptive behaviors [1]. WPV towards healthcare workers has become a warning global issue, with the incidence varying from 8 to $38 \%$ [2]. WPV can occur in various manners, ranging from verbal threats to physical assaults. Noticeably, WPV against medical workers is greater in psychiatric wards than in other departments (emergency department, medical and surgical wards, outpatient, and laboratory service) [3]. It has been asserted that, among psychiatric nurses, the incidence of WPV during their career was approximately $100 \%[4,5]$. Other studies reported that approximately 56.1 to $70 \%$ of psychiatric nurses expressed experiences of being physically assaulted by patients at the workplace [6, 7]. In China, WPV-related issues have become increasingly serious, with approximately 82.4 to $94.6 \%$ of Chinese psychiatric nurses reporting that they had suffered from at least one type of WPV in the last year, with the incidences of verbal abuse, physical assaults, and sexual harassment being 78.6 to $92.1 \%, 61.5$ to $81.9 \%$, and 18.6 to $42.9 \%$, respectively $[8,9]$.

The high incidence of WPV in mental health settings has caused a series of negative impacts among nurses, with exposure to WPV usually leading to physical injuries. An investigation by Yang et al., [9] noted that perpetrators, who had physically assaulted psychiatric nurses, had done so by bumping, pushing, gripping, biting, and even punching them. A survey among psychiatric nurses showed that $26 \%$ of them were seriously injured due to WPV, sustaining wounds like skin injuries, eye injuries, bone fractures, and permanent disabilities [10]. Moreover, a recent study reported that WPV contributed to increases in sick-leave taking among psychiatric nurses [11]. Besides physical injuries, Needham et al. [12] discovered that WPV also caused certain critical, nonsomatic negative effects on psychiatric nurses. Exposure to WPV resulted in bio-physiological (depression, anxiety, and fear), cognitive (thinking of oneself as disrespected, violated, threatened, and robbed of one's rights), emotional (anger, exhaustion, guilt, and selfblame), and social effects (doubts on job appropriateness and sense of insecurity) among psychiatric nurses, with some participants being diagnosed with post-traumatic stress disorder (PTSD). Approximately $75 \%$ of assaulted psychiatric nurses had complained that WPV had caused psychological burden [13]. Studies congruously claimed that WPV was a vital factor leading to anxiety $(\mathrm{r}=0.242$, $P<0.01)$ and depression $(\mathrm{r}=0.115, P<0.01)$ [13-15]. A recent study verified that WPV was significantly correlated with a higher job burnout level among nurses because the exposure to it led to both depersonalization and emotional exhaustion [9]. Another study showed that, among psychiatric nurses, exposure to WPV increased work-based stress and job burnout, and reduced their professional quality of life as a direct consequence [7].

The high incidence and severe impacts of WPV has subsequently increased public concern around it. Empirical findings summarized WPV as being associated with the characteristics of patients, nurses, institutes, and general society $[8,14,16-20]$. On one hand, patients with mental illnesses, poor treatment adherence, substance abuse, and aggressive behaviors were found to have a higher risk of posing WPV against psychiatric nurses [21]. Furthermore, nurses who had less work experience, less training, lacked de-escalating techniques, engaged in rude behaviors, and were mentally unwell $[13,15]$, were found to more frequently suffer WPV [19]. Additionally, empirical studies have also found that those wards with low quality environments and poor decorations resulted in patients' unpleasant experiences and views around being hospitalized, which would be expressed via their WPV [22, 23]. Furthermore, sociocultural factors set the tone for the overall social atmosphere influencing public attitudes on violence, following which, the acquiescence of violent behaviors from local cultures may have exacerbated WPV incidences against nurses [19].

Having discovered various factors contributing to WPV, strategies reducing its incidence and negative impacts have been developed accordingly. Occupational Safety and Health Administration (OSHA) guideline indicates that WPV prevention program should be based on the simultaneous implementation of organizational measures, administrative measures, and staff training [24]. Interventions targeted at enhancing staffing levels, restructuring the workplace environments, promoting 
work organization, improving nurse-patient therapeutic relations, and training medical workers have all proven effective in alleviating WPV $[19,20,25,26]$. Notably, substantial evidence has found that the promotion of improved de-escalation skills among psychiatric nurses is the most widely acknowledged intervention strategy $[22,27-33]$. Experts have reached a consensus that deescalation (DE) technique is the first-line WPV management strategy during early incidence stages $[34,35]$. DE refers to a range of skills involving averting conflicts through emotional regulation and self-management techniques [36]. In the psychiatric nursing context, studies have shed light on the contents of DE. It has been proposed that DE should focus on nurse-patient interactions, patient engagements, choosing appropriate intervention times, ensuring mutual safety, confirming patients' autonomy, limit-setting, and authoritative interventions [37, 38]. Another study by Hallett and Dickens [39], using concept analysis, emphasized that DE was achieved through techniques around self-regulation, communication, assessment, action, and safety maintenance [39]. The application of DE has had positive impacts on improving nurses' capacities, as well as on nurse-patient relationships, while reducing the use of coercive strategies by nurses (including seclusion, physical restraints, and mechanical restraints). After comparing pre- and post- results of the De-escalating Aggressive Behavior Scale, Nau et al., [40] suggested that the training of DE enhanced student nurses' performances in dealing with WPV (with scores for untrained $=3.01$ vs. trained $=3.61$ ). Another study also found that nurses receiving DE training possessed greater self-perceived confidence than those without, demonstrating that this form of preparation effectively enhanced nurses' performances by strengthening their confidence levels in dealing with WPV [41]. In addition, Fröhlich et al., [42] highlighted DE training's role in helping to cultivate a harmonious atmosphere within psychiatric wards by improving patients' coherence and subjective safety. Most importantly, the application of DE techniques decreases the use of coercive strategies. Empirical studies verified that DE training, targeting psychiatric nurses, reduced the use of physical restraints by approximately 26.4 to $74.0 \%$, and had cut down their likely duration and resultant adverse effects [43]. Current findings have confirmed that DE is a significantly utilized approach in dealing with WPV as well as in reducing the use of coercion, suggesting that $\mathrm{DE}$ is an indispensable component of standardized training programs for psychiatric nurses [29, 41, 44, 45]. However, the presented studies all possesses some limitations. First, among most studies, DE training is combined with other components concurrently, such as improved staffing levels, leadership styles, and risk assessments, and, therefore, the actual efficacy of DE itself remains unclear. Second, studies concerning DE provides weak creditability due to their lack of trial-based evidence [46]. Third, the characteristics of the DE training programs used among the current studies varies from one to another because its design needs to be matched to the environmental and socio-cultural factors- hence, the findings of Western studies might not be accurate in China. Last, very few studies simultaneously appraise the effectiveness of DE training via the improvement of nurses' capacities and objective indicators.

\section{Objectives}

Based on a literature review, and through using the Delphi method, a program has been developed in order to improve nurses' WPV coping capacities. This program is named after the first letter of each core component, which are Communication, Response, Solution, Care, and Environment (CRSCE), respectively. The aim of this study is to evaluate the effectiveness of a DE training program using the CRSCE core components among Chinese psychiatric nurses.

\section{Methods}

\section{Trial design}

The CRSCE program is a multi-center, single blinded, cluster randomized controlled trial with a 6-month follow-up period. All stages of this trial are in accordance with the CONSORT guidelines.

\section{Settings and participants}

This trial will be conducted among 6 major public psychiatric hospitals in Guangdong, China. The involved psychiatric hospitals are Guangzhou Mental Health Center (GZ), Shenzhen Mental Health Center (SZ), the Third Hospital of Foshan City (FS), the Second Hospital of Huizhou (HZ), Shantou Mental Health Center (ST), and the Third Hospital of Meizhou (MZ). The number of wards (secured and non-secured) and nurses of the involved hospitals are shown in Table 1. This study has gained ethical approval from the IRB of GZ. Executives from the involved institutes will be informed and asked for their permission to conduct the study, with the help of the nurses. Informed consent will be obtained from all participants before they complete the surveys.

\section{Inclusion criteria}

Aged from 18 to 60 years.

Registered nurses engaging in mental healthcare.

Are employed as full-time nurses.

\section{Exclusion criteria}

Student nurses and nursing interns.

Personnel taking refresher trainings at engaged wards. 
Table 1 Numbers of wards and nurses of recruited hospitals (secured and non-secured)

\begin{tabular}{|c|c|c|c|c|c|c|}
\hline \multirow[t]{2}{*}{ Hospital } & \multicolumn{3}{|l|}{ Non-secured ward } & \multicolumn{3}{|l|}{ Secured ward } \\
\hline & Number of wards & Number of beds & Number of nurses & Number of wards & Number of beds & Number of nurses \\
\hline$\overline{G Z}$ & 3 & 120 & 65 & 14 & 865 & 322 \\
\hline$S Z$ & 1 & 45 & 18 & 10 & 623 & 297 \\
\hline FS & 1 & 106 & 29 & 8 & 816 & 243 \\
\hline $\mathrm{HZ}$ & 1 & 44 & 20 & 7 & 906 & 291 \\
\hline ST & 3 & 60 & 46 & 8 & 620 & 231 \\
\hline$M Z$ & 1 & 60 & 20 & 7 & 700 & 220 \\
\hline
\end{tabular}

\section{Interventions}

Participants in the control group will receive routine WPV management training, participants of the intervention group will undergo the same training while additionally receiving CRSCE-based training. CRSCE is a 5module training program, composing 104 learning hours, which will be completed in 3 months. The modules, objectives, and learning hours of routine WPV management training and the CRSCE program are presented in Table 2.

\section{Outcomes}

Primary outcomes are objective clinical indicators of the included wards, which will be extracted from the hospital information systems and their annual reports. The objective indicators include the frequency of WPV, injuries caused by WPV, and the use of coercion (physical restraint and seclusion). The objective indicators will be calculated as follows:

a) monthly WPV frequency = monthly numbers of WPV event / total monthly patient days $\times 1000 \%$;

b) monthly frequency of injuries caused by WPV = monthly numbers of injuries caused by WPV / total monthly patient days $\times 1000 \%$ and;

c) monthly frequency of physical restraint (or seclusion $)=$ monthly numbers of patient days of physical restraint (or seclusion) / total monthly patient days $\times 1000 \%$.

Secondary outcomes are collected in order to evaluate the impacts on the nurses. The De-escalating Aggressive Behavior Scale (DABS), Confidence in Coping with Patient Aggression Instrument (CCPAI), Maslach Burnout Inventory-General Survey (MBI-GS), and Professional Quality of Life Scale (Pro QOL), will all be used to evaluate the capacity of DE, confidence of DE, level of job burnout, and professional quality of life, respectively. The above survey instruments will be used after obtaining licenses. The flow chart of this study is presented in Fig. 1.

\section{Sample size}

Sample size estimation is based on monthly frequency of WPV. Using the study by I. et al., (2004), we set a significant change of $12.1 \%$ (decreased from $17.8 \%$ by $5.70 \%$ ), alpha error of 0.05 , beta error of 0.20 , the estimated number $\left(\mathrm{N}_{\text {simple }}\right)$ of monthly records is 29 per group for simple randomized control trial [47]. The intra-class correlation coefficients (ICC), explains the inflation factor of cluster randomized controlled design trial, is set as 0.05 in proposed study [48]. Based on the numbers of wards of $\mathrm{MZ}$ and $\mathrm{HZ}(n=8)$, the minimum number of 6-month follow-up record $(\mathrm{m})$ is 48 . The sampling size of cluster randomized controlled trial ( $\left.\mathrm{N}_{\text {cluster }}\right)$ is calculated as: $\mathrm{N}_{\text {cluster }}=\left[1+\left(\mathrm{m}^{-1}\right) * \mathrm{ICC}\right] * \mathrm{~N}_{\text {simple }} \approx 98$. The minimum number of recruited hospitals of each group $(\mathrm{N})$ is calculated as: $\mathrm{N}=\mathrm{N}_{\text {cluster }} / \mathrm{m} \approx 2.04<3$, suggesting at least 3 hospitals per group.

\section{Randomization}

This is a cluster randomized controlled trial. The randomization unit is every involved psychiatric hospital. Involved psychiatric hospitals will be consecutively coded from 1 to 6 by a statistician not actively engaging in this study. By using an online random number generator, hospitals will be assigned to either the intervention or control group according to a 1:1 ratio. The statistician will then inform the research coordinator of the group allocations. Afterwards, the training schedule of each hospital will be designed according to its allocation. To ensure justice, when the intervention group has completed the CRSCE-based program, and follow-up data have been collected, the control group will also receive the same CRSCE-based training.

\section{Blinding}

This is a single-blinded study. Engaged nurses and their managers will not be aware of their hospital's allocation. The surveys will be completed by research assistants who are not involved in the CRSCE training program. 
Table 2 Modules, objectives, and learning hours of routine WPV management training and CRSCE

\begin{tabular}{|c|c|c|c|c|c|c|c|}
\hline \multirow{2}{*}{\multicolumn{2}{|c|}{ Module }} & \multirow[t]{2}{*}{ Content } & \multirow[t]{2}{*}{ Objects } & \multicolumn{2}{|l|}{ Hours } & \multirow{2}{*}{$\begin{array}{l}\text { Routine WPV } \\
\text { management } \\
\text { training }\end{array}$} & \multirow{2}{*}{$\begin{array}{l}\text { CRSCE } \\
\text { training }\end{array}$} \\
\hline & & & & Lecture & Practice & & \\
\hline \multirow{6}{*}{\multicolumn{2}{|c|}{$\begin{array}{l}\text { Routine WPV } \\
\text { management training }\end{array}$}} & $\begin{array}{l}\text { Basic Communication } \\
\text { Skills of Nursing }\end{array}$ & $\begin{array}{l}\text { To understand the concept } \\
\text { of communication skills and } \\
\text { its attributes } \\
\text { To understand different types } \\
\text { of communication skills } \\
\text { To learn how to interact with } \\
\text { patients in practice }\end{array}$ & 4 & - & $\checkmark$ & $\checkmark$ \\
\hline & & $\begin{array}{l}\text { Communication Skills in } \\
\text { Mental Health Care }\end{array}$ & $\begin{array}{l}\text { To identify the attribute of } \\
\text { communication skills in mental } \\
\text { health care } \\
\text { To distinguish the difference of } \\
\text { communication skills between } \\
\text { mental health and general nursing } \\
\text { To learn how to interact with } \\
\text { psychiatric patients }\end{array}$ & 4 & 4 & $\checkmark$ & $\checkmark$ \\
\hline & & Risk Assessment of Violence & $\begin{array}{l}\text { To understand the types of WPV } \\
\text { To learn how to use different } \\
\text { assessment tools } \\
\text { To discuss advantage and } \\
\text { disadvantage of assessment tools }\end{array}$ & 4 & - & $\checkmark$ & $\checkmark$ \\
\hline & & $\begin{array}{l}\text { The Ethic and Law in } \\
\text { Metal Health Care }\end{array}$ & $\begin{array}{l}\text { To discuss the ethical issues in } \\
\text { mental health care } \\
\text { To discuss how nurses to balance } \\
\text { the ethical issues and law in mental } \\
\text { health care }\end{array}$ & 4 & - & $\checkmark$ & $\checkmark$ \\
\hline & & De-escalation & $\begin{array}{l}\text { To know the concept of } \\
\text { De-escalation } \\
\text { To identify the attributes of } \\
\text { De-escalation } \\
\text { To discuss the key components } \\
\text { contribute to successful } \\
\text { de-escalation }\end{array}$ & 4 & - & $\checkmark$ & $\checkmark$ \\
\hline & & Practical WPV coping skills & $\begin{array}{l}\text { To learn the breakaway techniques, } \\
\text { holding methods } \\
\text { To learn the control and restraint } \\
\text { methods }\end{array}$ & 4 & 8 & $\checkmark$ & $\checkmark$ \\
\hline \multirow[t]{5}{*}{$\begin{array}{l}\text { CRSCE } \\
\text { training }\end{array}$} & \multirow[t]{2}{*}{ Communication } & $\begin{array}{l}\text { How to Build the Therapeutic } \\
\text { Nurse-Patient Relationship }\end{array}$ & $\begin{array}{l}\text { To identify the factors that influence } \\
\text { therapeutic relationship } \\
\text { To identify the key components of } \\
\text { building the therapeutic relationship } \\
\text { with patients } \\
\text { To learn how to build therapeutic } \\
\text { nurse-patient relationship using } \\
\text { communication skills }\end{array}$ & 4 & 4 & NA & $\checkmark$ \\
\hline & & $\begin{array}{l}\text { The Communication Skills } \\
\text { with Aggressive Patients }\end{array}$ & $\begin{array}{l}\text { To learn the communication skills } \\
\text { with aggressive patients }\end{array}$ & 4 & 4 & NA & $\checkmark$ \\
\hline & \multirow[t]{3}{*}{ Response } & The Early Stage Signal of WPV & $\begin{array}{l}\text { To identify the early stage signal } \\
\text { of WPV } \\
\text { To discuss and learn what a } \\
\text { nurse should do when he/she } \\
\text { has identified a patient is in } \\
\text { WPV early stage }\end{array}$ & 4 & 4 & NA & $\checkmark$ \\
\hline & & $\begin{array}{l}\text { What Is Your FIRST Reaction } \\
\text { When WPV Happens? }\end{array}$ & $\begin{array}{l}\text { To recall nurses' memories of facing } \\
\text { violence } \\
\text { To share nurses' experience of coping } \\
\text { with violence } \\
\text { To refresh and discuss the appropriate } \\
\text { method to manage WPV }\end{array}$ & 4 & - & NA & $\checkmark$ \\
\hline & & $\begin{array}{l}\text { When WPV Happens, } \\
\text { What Should We Do? }\end{array}$ & $\begin{array}{l}\text { To learn how to response WPV } \\
\text { To discuss the alternatives of WPV }\end{array}$ & 4 & 2 & NA & $\checkmark$ \\
\hline
\end{tabular}


Table 2 Modules, objectives, and learning hours of routine WPV management training and CRSCE (Continued)

\begin{tabular}{|c|c|c|c|c|c|c|}
\hline \multirow[t]{2}{*}{ Module } & \multirow[t]{2}{*}{ Content } & \multirow[t]{2}{*}{ Objects } & \multicolumn{2}{|l|}{ Hours } & \multirow{2}{*}{$\begin{array}{l}\text { Routine WPV } \\
\text { management } \\
\text { training }\end{array}$} & \multirow{2}{*}{$\begin{array}{l}\text { CRSCE } \\
\text { training }\end{array}$} \\
\hline & & & Lecture & Practice & & \\
\hline & $\begin{array}{l}\text { What Is the Influence } \\
\text { of WPV on You? }\end{array}$ & $\begin{array}{l}\text { To discuss and share the } \\
\text { influence of WPV on individual }\end{array}$ & 4 & - & NA & $\checkmark$ \\
\hline \multirow[t]{3}{*}{$\begin{array}{l}\text { Solution-Focused } \\
\text { Technique }\end{array}$} & $\begin{array}{l}\text { Cognitive Positive } \\
\text { Psychology }\end{array}$ & $\begin{array}{l}\text { To learn the concept of cognitive } \\
\text { positive psychology and how to } \\
\text { use it in clinical work }\end{array}$ & 4 & 4 & NA & $\checkmark$ \\
\hline & $\begin{array}{l}\text { The Concept and Principle } \\
\text { of Solution-Focused } \\
\text { Technique in Nursing }\end{array}$ & $\begin{array}{l}\text { To learn the concept and } \\
\text { principle of solution-focused } \\
\text { technique }\end{array}$ & 4 & - & NA & $\checkmark$ \\
\hline & $\begin{array}{l}\text { The Five Stages of } \\
\text { Psychological Intervention } \\
\text { of Solution-Focused } \\
\text { Technique and Its } \\
\text { Application }\end{array}$ & $\begin{array}{l}\text { To identify the five stages of } \\
\text { psychological intervention of } \\
\text { solution-focused technique } \\
\text { To learn using the five stages } \\
\text { of psychological intervention } \\
\text { in practice }\end{array}$ & 4 & 2 & NA & $\checkmark$ \\
\hline \multirow[t]{3}{*}{ Care } & $\begin{array}{l}\text { The History and Development } \\
\text { of Humane Care Service }\end{array}$ & $\begin{array}{l}\text { To understand the history and } \\
\text { development of humane care } \\
\text { service } \\
\text { To identify the key elements of } \\
\text { humane care service }\end{array}$ & 4 & - & NA & $\checkmark$ \\
\hline & $\begin{array}{l}\text { The Relationship Between } \\
\text { Humane Care Service and WPV }\end{array}$ & $\begin{array}{l}\text { To discuss the relationship } \\
\text { between humane care service } \\
\text { and WPV } \\
\text { To learn proving humane care } \\
\text { to aggressive patients }\end{array}$ & 4 & 4 & NA & $\checkmark$ \\
\hline & $\begin{array}{l}\text { The Humane Care Service } \\
\text { in Mental Health Care }\end{array}$ & $\begin{array}{l}\text { To identify the humane care } \\
\text { service in mental health care } \\
\text { To discuss what nurses can do to } \\
\text { provide the humane care service } \\
\text { to psychiatric patients }\end{array}$ & 4 & 4 & NA & $\checkmark$ \\
\hline \multirow[t]{2}{*}{ Environment } & $\begin{array}{l}\text { The Innovation of } \\
\text { Environment in Mental } \\
\text { Health Care }\end{array}$ & $\begin{array}{l}\text { To understand the concept of } \\
\text { environment in mental health } \\
\text { care } \\
\text { To understand the change } \\
\text { process and development of } \\
\text { environment in mental health } \\
\text { care }\end{array}$ & 8 & 4 & NA & $\checkmark$ \\
\hline & $\begin{array}{l}\text { Evidence Base Practice: The } \\
\text { Relationship Between Ward } \\
\text { Environment and WPV }\end{array}$ & $\begin{array}{l}\text { To discuss how environment } \\
\text { affects the WPV } \\
\text { To find out the environmental } \\
\text { hazards of WPV through literature } \\
\text { review } \\
\text { To implement achievable } \\
\text { improvement of ward } \\
\text { environment }\end{array}$ & 8 & 8 & NA & $\checkmark$ \\
\hline \multicolumn{3}{|c|}{$\checkmark$ : Included modules NA: Not Available } & \multicolumn{2}{|c|}{$\begin{array}{l}\text { Total Learning } \\
\text { Hours }\end{array}$} & $36 \mathrm{~h}$ & $140 \mathrm{~h}$ \\
\hline
\end{tabular}

\section{Data collection}

Primary outcomes will be continuously collected every month by extracting data from the hospital information systems (HIS) and their annual reports. Secondary outcomes are collected at baseline $\left(\mathrm{T}_{0}\right), 3$ months after intervention ( $\mathrm{T}_{1}$, the end of intervention), and 6 months after intervention ( $\mathrm{T}_{2}$, follow-up). Data collection will be completed by research assistants who are not aware of this study's design.

\section{Statistical methods}

Statistical analysis will be performed using SPSS version 22.0 software (SPSS Inc., Chicago, IL, USA). Descriptive statistics will be reported as frequencies and percentages, if applicable. The Shapiro-Wilk test will be used in order to examine the distributions of the continuous outcomes. Quantitative variables will be presented using means and standard deviations or as the median and interquartile range. A Student's t-test, Mann-Whitney U test, Chi-square test, or Fisher's exact test will be 


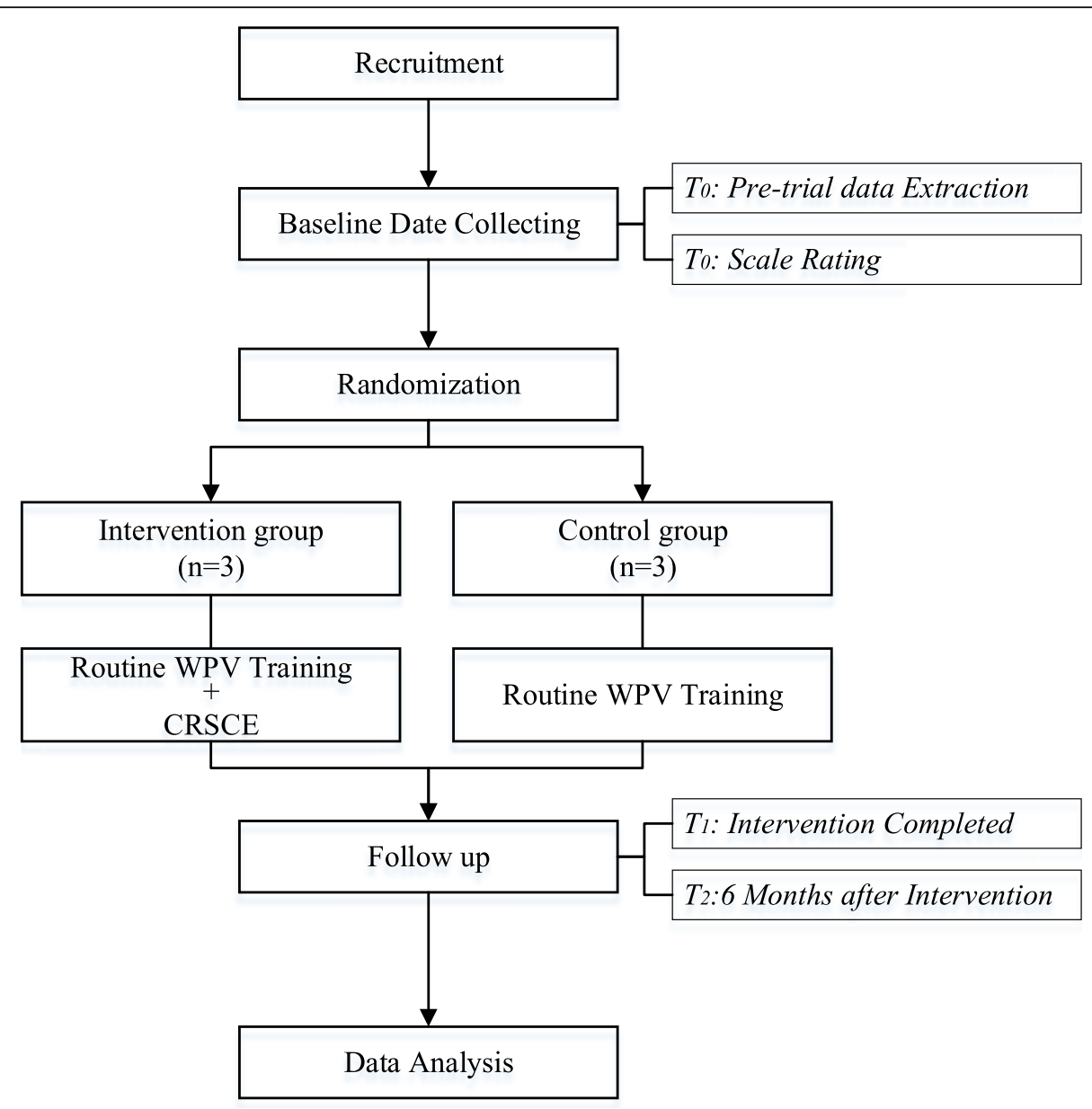

Fig. 1 Trial Flow Chart

adopted to compare the groups according to their normality distributions. Additionally, a repeated ANOVA will be used to explore the effectiveness of the CRSCE training program and further regression analysis will be performed, if appropriate. The statistical significance will be set at $P<0.05$, two tailed, with a 95\% confidence interval $(C I)$.

\section{Study quality control}

All instruments used in this study have been examined for their validity and reliability. Part-time nurses are not available among the 6 involved institutes. Involved psychiatric hospitals are located in different cities of Guangdong Province, and therefore possible contamination between groups is unlikely. To improve the homogeneity of the intervention, during this study newly employed nurses of the involved institutes will be assigned to the training program and will be evaluated accordingly. Short-duration refresher courses will be monthly arranged to maintain accreditation and competency among psychiatric nurses of intervention group.

\section{Discussion}

WPV is prevalent in psychiatric hospitals, resulting in critically adverse impacts on nurses. This study will examine the effectiveness of interventions of reducing these WPV impacts. DE training is a recommended intervention for helping psychiatric nurses in dealing with WPV, but more trial-based evidences are needed in order to support its effectiveness. To the best of our knowledge, this is the first study protocol evaluating the effectiveness of DE using a cluster randomized controlled trial. Compared to routine WPV management training, CRSCE is an additional and innovative training program for psychiatric nurses. The modules of CRSCE are expected to address the crucial components of $\mathrm{DE}$, as well as the general mental health service backgrounds in China. Usually, the patient's unmet demands are found to be a prominent cause of WPV; therefore, solution-oriented and humane care approaches are warranted, with these being achieved by appropriate communications and responses by healthcare professionals. In addition, therapeutic environments also have been found to influence the occurrence of WPV. Poor 
therapeutic environments have been found to cause greater numbers of complaints by patients around hospitals and medical staff, which, to some extent, could result in greater WPV incidences [24]. In China, the governmental investment into mental health services was limited [49], with this inadequate financial support hindering the upgrading of therapeutic environments in psychiatric hospitals. Thus, this is why a therapeutic environment module is to be included in this study. The major strength of this study is that all of the included modules (Communication, Response, Solution, Care, and Environment) have been examined by empirical researches. Study by Magnavita [26] highlighted that effective communication, WPV preventing solution, response by identifying violence-prone individuals, and rearranging environment, were crucial components reducing WPV (assault rate declined from $0.24 \pm 0.02$ to $0.04 \pm 0.03, t=14.4, P<0.01)$ in psychiatric units [26]. In addition to the components mentioned by Magnavita [26], OSHA WPV preventing guideline and Irish physical reduction strategy simultaneously propose, providing humane care (i.e. trauma informed care) is a successfully instituted approach in psychiatric hospitals in preventing WPV and reducing the use of physical restraint $[24,50]$. Therefore, the employed modules are expected to reduce WPV incidence and WPV resultant impacts.

The outcomes of the CRSCE training program, as analyzed by this study, will present helpful and practical evidence for healthcare providers and policy makers. The primary outcome data used will be the objective indicators of WPV, extracted from hospital incident data, and this will contribute to the evaluation of the CRSCE training program. The secondary outcome will assess the influence of CRSCE training program on nurses by using questionnaires. These results will inform practitioners and policy makers as to how and to what extent CRSCE improves psychiatric nurses' WPV coping capacities. In proposed study, we hypothesize the frequency of WPV, of injuries caused by WPV, and of coercion (physical restraint and seclusion), will be decreased because CRSCE training program would help preventing WPV in early stage. Besides, after intervention, we are expected to see the increased scores of DABS, CCPAI, and Pro QOL; and a significant decline in MBI-GS score. These might reflect CRSCE training program improves the capacity and confidence in dealing with WPV, and helps to relieve job burnout symptom.

However, this study has a few limitations. First, this study only includes psychiatric nurses. Psychiatrists, unlicensed nursing assistants (UNA), and other professionals will not be recruited. However, the practices of UNA are supervised by registered nurses and WPV alleviation is usually directed by nurses, meaning that psychiatric nurses are the most affected population group in this regard. Thus, training involving registered psychiatric nurses will be the most apropos approach. Second, this study applies a single-blinded design, and, as a result, the CRSCE instructors might be aware of their own group allocation because they will be knowledgeable of the structure of both the CRSCE and routine training programs. To eliminate this bias, primary outcome recordings and surveys will be completed by research assistants who are not aware of this study's design. Third, CRSCE training program might affect the reporting behavior because it might enhance WPV awareness among psychiatric nurses, which would influence the generalization of research data in result. This reporting bias would be controlled to the most extent as all recruited hospitals are required to follow the national guideline of reporting nursing indicators [51]. Last, uncontrollable factors contributing to increased rates of aggression might influence the objective indicators. Despite the limitations above, this study is expected to evaluate the effectiveness of the CRSCE training program on WPV alleviation and its inherent benefits for nurses.

\section{Trial status}

The proposed trial had been prospectively registered at the Chinese Clinical Trial Registry (Registration Number: ChiCTR1900022211).

\section{Abbreviations}

CCPAl: Confidence in Coping with Patient Aggression Instrument; DABS: Deescalating Aggressive Behavior Scale; DE: De-escalation; MBI-GS: Maslach Burnout Inventory-General Survey; Pro QOL: Professional Quality of Life Scale; WPV: Workplace violence

\section{Acknowledgements}

We would like to acknowledge Huiai Violence Prevention and Management Group (HVPM) for dedication in CRSCE training program. Besides, the first author, Junrong YE, is very delighted to welcome his daughter Youyou YE came to the world on December 5, 2019.

\section{Authors' contributions}

This manuscript was in collaboration between all authors. JY, AX, and CW conceived this study. ZX, LY, SL, and JL participated in sampling methods design. $Y L, Y X$, and $Y Z$ participated in statistical methods design. JY, $A X$, and ZX drafted and revised this protocol. All authors had read and approved the final manuscript. JY, AX, and CW were listed as co-first authors because they contributed equally to the study. JY was assigned to be the corresponding author.

\section{Funding}

This study is funded by governmental program named Guangdong Science of Medical Technique Program, the grant number is A2018440; by

Guangzhou Health Science and Technology Guidance Project, the grant number is 906283101031 . These funding will support the design and data collection of proposed study.

Availability of data and materials

The datasets analyzed during the current study are not publicly available due because further data analysis may be undergoing, but are available from the corresponding author on reasonable request. 


\section{Ethics approval and consent to participate}

The proposed study had obtained ethics approval from IRB of Affiliated Brain Hospital of Guangzhou Medical University. Written informed consent will be obtained from participants before the surveys.

\section{Consent for publication}

The details and figure of this manuscript will be freely available on the internet and may be seen by the general public.

\section{Competing interests}

The authors declare that they have no competing interests.

\section{Author details}

'Department of Nursing Administration, Affiliated Brain Hospital of Guangzhou Medical University (Guangzhou Huiai Hospital), Guangzhou 510370, China. ${ }^{2}$ Department of Social Psychiatry, Affiliated Brain Hospital of Guangzhou Medical University (Guangzhou Huiai Hospital), Guangzhou, China. ${ }^{3}$ Department of Traditional Chinese Medicine, Affiliated Brain Hospital of Guangzhou Medical University (Guangzhou Huiai Hospital), Guangzhou, China. ${ }^{4}$ Department of Early Intervention, Affiliated Brain Hospital of Guangzhou Medical University (Guangzhou Huiai Hospital), Guangzhou, China. ${ }^{5}$ Department of Adult Psychiatry, Affiliated Brain Hospital of Guangzhou Medical University (Guangzhou Huiai Hospital), Guangzhou, China. ${ }^{6}$ Department of Cardiothoracic Surgery, Jingzhou Central Hospital, Jingzhou, China. ${ }^{7}$ Department of Intensive Care Unit, West China Hospital of Sichuan University, Chengdu, China.

\section{Received: 18 October 2019 Accepted: 2 July 2020}

\section{Published online: 10 July 2020}

\section{References}

1. Barling J, Dupré KE, Kelloway EK. Predicting workplace aggression and violence. Annu Rev Psychol. 2009:60:671-92.

2. World Health Organization. Workplace violence. 2012. http://www.who.int/ violence_injury_prevention/injury/work9/en/print.htm. Accessed 20 May 2015.

3. Magnavita N, Heponiemi T. Violence towards health care workers in a public health Care Facility in Italy: a repeated cross-sectional study. BMC Health Serv Res. 2012;12:108.

4. Carmel $H$, Hunter M. Staff injuries from inpatient violence. Hosp Community Psychiatry. 1989;40:41-6.

5. Ewa M, Eija V. Threats and violence in Swedish care and welfare--magnitude of the problem and impact on municipal personnel. Scand J Caring Sci. 2010;16:376-85.

6. Abderhalden C, Needham I, Friedli TK, Poelmans J, Dassen T. Perception of aggression among psychiatric nurses in Switzerland. Acta Psychiatr Scand. 2010;106:110-7.

7. Itzhaki M, Bluvstein I, Bortz AP, Kostistky H, Noy DB, Filshtinsky V, et al. Mental health nurse's exposure to workplace violence leads to job stress, which leads to reduced professional quality of life. Front Psychiatry. 2018;9: $1-6$

8. Zeng JY, An FR, Xiang YT, Qi YK, Ungvari GS, Newhouse R, et al. Frequency and risk factors of workplace violence on psychiatric nurses and its impact on their quality of life in China. Psychiatry Res. 2013;210:510-4.

9. Yang BX, Stone TE, Petrini MA, Morris DL. Incidence, type, related factors, and effect of workplace violence on mental health nurses: a cross-sectional survey. Arch Psychiatr Nurs. 2018;32:31-8.

10. Moylan LB, Cullinan M. Frequency of assault and severity of injury of psychiatric nurses in relation to the nurses' decision to restrain. J Psychiatr Ment Health Nurs. 2011;18:526-34.

11. Phillips JP. Workplace violence against health Care Workers in the United States. N Engl J Med. 2016;374:1661-9.

12. Needham I, Abderhalden C, Halfens Phd RJG, Fischer JE, Dassen T. Nonsomatic effects of patient aggression on nurses: a systematic review. J Adv Nurs. 2005:49:283-96

13. Hsieh H-F, Shen S-H, Li Y-C. Predictors of depressive symptoms among psychiatric nurses who suffered from workplace violence. J Eng Appl Sci. 2017:12:3218-21

14. Chen WC, Huang CJ, Chen CC, Der Wang J. The incidence and risk factors of workplace violence towards female nurses reported via internet in an acute psychiatric hospital. Arch Environ Occup Health. 2011;66:100-6.
15. Zhao S, Xie F, Wang J, Shi Y, Zhang S, Han X, et al. Prevalence of workplace violence against Chinese nurses and its association with mental health: a cross-sectional survey. Arch Psychiatr Nurs. 2018;32:242-7.

16. Ridenour M, Lanza M, Hendricks S, Hartley D, Rierdan J, Zeiss R, et al. Incidence and risk factors of workplace violence on psychiatric staff. Work. 2015;51:19-28.

17. Tonso MA, Prematunga RK, Norris SJ, Williams L, Sands N, Elsom SJ. Workplace violence in mental health: a Victorian mental health workforce survey. Int J Ment Health Nurs. 2016;25:444-51.

18. Saragoza P, White SG. Workplace violence: practical considerations for mental health professionals in consultation, assessment, and Management of Risk. Psychiatr Clin North Am. 2016;39:599-610.

19. Hamrin V, lennaco J, Olsen D. A review of ecological factors affecting inpatient psychiatric unit violence: implications for relational and unit cultural improvements. Issues Ment Health Nurs. 2009:30:214-26.

20. Gillespie GL, Gates DM, Miller M, Howard PK. Workplace violence in healthcare settings: risk factors and protective strategies. Rehabil Nurs. 2010; 35:177-84.

21. D'Ettorre G, Pellicani V. Workplace violence toward mental healthcare workers employed in psychiatric wards. Saf Health Work. 2017;8:337-42.

22. Vaaler $A E$, Morken $G$, Linaker OM. Effects of different interior decorations in the seclusion area of a psychiatric acute ward. Nord J Psychiatry. 2005;59: $19-24$.

23. Van Wijk E, Traut A, Julie H. Environmental and nursing-staff factors contributing to aggressive and violent behaviour of patients in mental health facilities. Curationis. 2014;37:1-9.

24. Occupational Safety and Health Administration. Guidelines for preventing workplace violence for healthcare and social service workers. 2016. https:// www.osha.gov/Publications/osha3148.pdf. Accessed 18 Mar 2020.

25. Cornaggia CM, Beghi M, Pavone F, Barale F. Aggression in psychiatry wards: a systematic review. Psychiatry Res. 2011;189:10-20.

26. Magnavita N. Violence prevention in a small-scale psychiatric unit: program planning and evaluation. Int J Occup Environ Health. 2011;17:336-44.

27. Xiao A, He H, Sun B, Rao D, Ning Y, Rosenheck RA. Comparison of attitudes of the psychiatrists and nurses towards patients with mental illness in a Chinese psychiatric hospital: implications for training. Asia Pac Psychiatry. 2016:8:104-5

28. Aixiang $X$, Junrong $Y$. Suggestion for reducing the use of physical restraint in mental health settings. Riv Psichiatr. 2017;52:212.

29. Ye J, Xiao A, Yu L, Guo J, Lei $H$, Wei $H$, et al. Staff training reduces the use of physical restraint in mental health service, evidence-based reflection for China. Arch Psychiatirc Nurs. 2017:32:488-94.

30. Abderhalden C, Needham I, Dassen T, Halfens R, Haug HJ, Fischer JE. Structured risk assessment and violence in acute psychiatric wards: randomised controlled trial. Br J Psychiatry. 2008;193:44-50.

31. Needham I, Abderhalden C, Meer R, Dassen T, Haug H, Halfens R, et al. The effectiveness of two interventions in the management of patient violence in acute mental inpatient settings: report on a pilot study. J Psychiatr Ment Health Nurs. 2004:11:595-601.

32. Olver J, Love M, Daniel J, Norman T, Nicholls D. The impact of a changed environment on arousal levels of patients in a secure extended rehabilitation facility. Australas Psychiatry. 2009;17:207-11

33. Scanlan JN. Interventions to reduce the use of seclusion and restraint in inpatient psychiatric settings: what we know so far a review of the literature. Int J Soc Psychiatry. 2010;56:412-23.

34. National Institute of Clinical Excellence. Violence: the short-term Management of Disturbed/violent behaviour in in-patient psychiatric settings and emergency departments. London: National Institute for Clinical Excellence; 2005.

35. Lavelle M, Stewart D, James K, Richardson M, Renwick L, Brennan G, et al. Predictors of effective de-escalation in acute inpatient psychiatric settings. J Clin Nurs. 2016;25:2180-8.

36. Research C, Guidelines A. The prevention and management of aggression a good practice statement; 1996.

37. Price $\mathrm{O}$, Baker J. Key components of de-escalation techniques: a thematic synthesis. Int J Ment Health Nurs. 2012;21:310-9.

38. Hallett N, Dickens GL. De-escalation: a survey of clinical staff in a secure mental health inpatient service. Int J Ment Health Nurs. 2015:24:324-33.

39. Hallett N, Dickens GL. De-escalation of aggressive behaviour in healthcare settings: concept analysis. Int J Nurs Stud. 2017:75:10-20. 
40. Nau J, Halfens R, Needham I, Dassen T. Student nurses' de-escalation of patient aggression: a pretest-posttest intervention study. Int J Nurs Stud. 2010;47:699-708.

41. Baig L, Tanzil S, Shaikh S, Hashmi I, Khan MA, Polkowski M. Effectiveness of training on de-escalation of violence and management of aggressive behavior faced by health care providers in public sector hospitals of Karachi. Pakistan J Med Sci. 2018;34:294-9.

42. Fröhlich D, Rabenschlag F, Schoppmann S, Borgwardt S, Lang UE, Huber CG. Positive effects of an anti-aggression and de-escalation training on ward atmosphere and subjective safety may depend on previous training experience. Front Psychiatry. 2018:9:134.

43. Bowers L, James K, Quirk A, Simpson A, Stewart D, Hodsoll J. Reducing conflict and containment rates on acute psychiatric wards: the Safewards cluster randomised controlled trial. Int J Nurs Stud. 2015;52:1412-22.

44. Stewart D, Van der Merwe M, Bowers L, Simpson A, Jones J. A review of interventions to reduce mechanical restraint and seclusion among adult psychiatric inpatients. Issues Ment Health Nurs. 2010;31:413-24.

45. Borckardt JJ, Madan A, Grubaugh AL, Danielson CK, Pelic CG, Hardesty SJ, et al. Systematic investigation of initiatives to reduce seclusion and restraint in a state psychiatric hospital. Psychiatr Serv. 2011;62:477-83.

46. Du Md, Wang X, Yin S, Shu W, Hao R, Zhao S, et al. De-escalation techniques for psychosis-induced aggression or agitation. Cochrane Database Syst Rev. 2017: 1-24.

47. Chow S-C, Shao J, Wang H, Lokhnygina Y. Sample size calculations in clinical Research. Third Edit. Boca Raton: Taylor \& Francis Group; 2018.

48. Loh DA, Choo WY, Hairi NN, Othman S, Mohd Hairi F, Mohd Mydin FH, et al. A cluster randomized trial on improving nurses' detection and management of elder abuse and neglect (I-NEED): study protocol. J Adv Nurs. 2015;71:2661-72

49. Xiang YT, Yu X, Sartorius N, Ungvari GS, Chiu HFK. Mental health in China: challenges and progress. Lancet. 2012;380:1715-6.

50. Mental Health Comission. Mental Health Commission Seclusion and Physical Restraint Reduction Strategy. Dublin; 2012. https://www.mhcirl.ie/File/ SecandPPR_KnowRev.pdf.

51. Nursing Center of National Hospital Administration Institute. Guidelines for Data Sets of Nursing-Sensitive Quality Indicators (In Chinese). 2018 Versi. Peking: People's Medical Publishing House; 2018.

\section{Publisher's Note}

Springer Nature remains neutral with regard to jurisdictional claims in published maps and institutional affiliations.

Ready to submit your research? Choose BMC and benefit from:

- fast, convenient online submission

- thorough peer review by experienced researchers in your field

- rapid publication on acceptance

- support for research data, including large and complex data types

- gold Open Access which fosters wider collaboration and increased citations

- maximum visibility for your research: over $100 \mathrm{M}$ website views per year

At $\mathrm{BMC}$, research is always in progress.

Learn more biomedcentral.com/submissions 